\title{
The Effect of Using a Teaching Strategy Based on the KWLH Learning Schedule to Gain the Concepts of Scientific Research Curricula among Princess Rahma University College Students
}

\author{
Dr. Maha Hamed Alsaaideh \\ Princess Rahma University College, \\ Al-Balqa Applied University, Jordan
}

Doi: 10.36941/jesr-2020-0026

\section{Abstract}

This study aimed to investigate the effect of using a teaching strategy based on the KWLH learning schedule to gain concepts of scientific research curricula among students of Princess Rahma University College. The study sample participants were intentionally chosen from students of Princess Rahma University College at Al-Balqa Applied University, who are enrolled in the research methodology course and its statistical methods. They were randomly assigned to two groups: an experimental group studied according to the teaching strategy based on the learning schedule KWLH, and a control group that studied according to the usual strategy. A test tool was implemented after verifying its validity and reliability, namely: Testing the concepts of scientific research methods. The study concluded that the teaching strategy based on the KWLH learning table was superior, and its percentage (16.24\%) of the variance in the dependent variable was explained. The results showed that there was no statistically significant difference in the acquisition of the concepts of scientific research methods due to gender or the interaction between teaching strategy and gender. There was also a lack of a statistically significant difference in the acquisition of the concepts of scientific research methods due to the university cumulative average, compared to the presence of a statistically significant effect attributed to the interaction between the teaching strategy and the cumulative rate in the acquisition of the concepts of scientific research methods.

Keywords: KWLH Learning Schedule Strategy, Scientific Research Curriculum Concepts, Princess Rahma University College Students

\section{Introduction to the Study}

The march of the educational process in our time has become a social and humanitarian project based on providing strategies to motivate the teacher's professional energies and capabilitiesto build the student's aptitude as a researcher and thinker. These strategies helpthe student learn and acquire concepts and information and develop thinking and research skills and problem solving. The teacher is provided modern teaching strategies that serve to increase the student's motivation toward learning and stimulate his attention and interests in a manner that encourages the student to participate positively and effectively in the educational situation, especially in light of the availability of different learning resources at the present time. This availability of learning resources contributes to the flexibility of changing the role of the teacher and the student in a positive way in the educational learning process, so that the teacher becomes the guide and mentor, and the student is 
responsible for his learning and is a researcher of knowledge and meaning-building which qualifies him to employ what he learned in new life situations; this is accomplished through employing modern teaching strategies that considerissues of meaningful learning, concept-building and absorbing accurate knowledge, taking into account individual differencesand self-learning. They create the potential for positive participation by all students. The learning technique KWLH (Know, Want, Learned, How) makes students the focus of the educational process and focuses on positive support of students, thereby increasing their self-confidence to learn academic concepts while taking into account the characteristics of students and their capabilities.

The KWL Learning Schedule strategy created by Donna Ogle in the USA was one of various educational strategies based on the metacognition concept that John Flavell first created in 1979 to refer to effective and meaningful learning (Alsoudi, 2017). Metacognitive strategies include a set of procedures for the learner to achieve effective active learning that makes learning based on the learner's activity and experiences. The learner's effectiveness is increased when dealing with different educational situations and develops his ability to manage his knowledge. The KWL learning schedule strategy helps the teacher in enabling his students to process the texts, no matter how difficult they are, by activating their previous knowledge. It strengthens the principle of self-learning among students and contributes to attracting their interest and encouraging them in the constant search for information (Al-Balawi, 2016).

The learning schedule strategy KWLH is considered an effective constructive learning strategy. It requires learners to summon their prior knowledge, and it is described as a strategy that has a positive impact on developing an understanding of the text read by students. The main steps of theKWL strategy are described by DonnaOgle: K- what I know about the subject (identifying previous knowledge) and the word "know" symbolizes previous knowledge; W- what I want to know about the subject, and the word "want" symbolizes the intended knowledge; L- what I already learned about the subject, and the word "learned" symbolizes the knowledge already acquired(Musabalat2o16, Bou Aisha2018). This strategy aims to help students understand the subject and employ it in a way that is consistent with the student's cognitive structure and in a manner that relies on activating the previous knowledge and making it a point of recall and acquisition of new information (Musabalat 2016, Bou Aisha 2018).

In this context, the KWL strategy is characterized by flexibility so that the teacher can adapt it to suit the students. In its essence, it depends on the student's self-questioning process to verify the type, nature, and amount of his knowledge and the appropriate methods for the assignment he is about to learn. There also is the possibility of adding a fourth step to establish the KWLH Learning ScheduleStrategy.It is represented by the letter H - How can more be learned (Bou Aisha, 2018). The word How indicates the development of information and the deepening of students' experiences about the concept from additional learning sources, while the fifth step, Summarizing, refers to the ability of students to write a summary of what was learned (Bou Aisha, 2018).

The success of the KWLH strategy depends on the role that the teacher plays towards students when implementing the strategy and the extent of his knowledge of the teacher's role. The main role of the teacher is to encouragestudents to identify their previous knowledge, and to generate questions for students that serve to stimulate their thinking and encourage them to come up with new ideas. The teacher should dialogue with students, organizing their knowledge and directing it within an effective organizational chart, promoting good ideas and correcting students' alternative perceptions by comparing what they have learned with what they believed. Immediate feedback should be provided to students. Teachers should assess students' performance and the degree to which they achieve the desired goals (Aram, 2012). The teacher also helps his students by highlighting the gaps and inconsistencies in the students' knowledge and guides them to create lists of things they want to know about the topic or questions they want to answer about it (Mardiana, 2016).

Since the KWL strategy stimulates students' thinking by promoting questioning and independent thinking and defining the goals that lead them to achieve them (Alsoudi, 2017), it is important in helping studentsidentify prior knowledge of the topic of the text being read, defining 
the purpose of reading, observing their understanding, evaluating their understanding of the text and the expansion of ideas beyond the text (Mardiana, 2016). The learner plays an important role during the application of the KWL or KWLH strategies, which is planning the goals and their sequences and achieving them and monitoring himself and his success in communicating these goals and evaluating the mistakes and challenges that face him, and all this is by activating his previous knowledge and linking it to new knowledge and practicing various educational activities, and the biggest burden falls on the learner who performs the questioning and self-questioning before, during, and after the learning process. To achieve this, there must be a set of attributes in the learner to do this role: cooperation with colleagues, interacting positively with others during activities, perseverance in learning, interest in feedback, realism, and the ability to employ knowledge acquired in different areas of life (Al-Otaibi, 2015).

Since sound conceptual knowledge is important for students'success in acquiring new concepts and is related to modifying wrong or unclear concepts to them, it was appropriate to choose a teaching strategy that contributes to improving students' learning of scientific research concepts and approaches and their perception as the concepts in the curriculum of scientific research are distinguished as having a special nature. The concepts are interrelated and cumulative and have repercussions and mutual effects among them, which may lead to students' misunderstanding of them. Alawin and Al-Ayasrah (2016) have indicated that learning concepts and acquiring them requires the use of teaching strategies and methods based on understanding and meaningful learning and activating the active role of the student in scientific activities. Use of the strategies take into account basic skills in thinking and ensures accuracy in its composition so that students retain it for a longer period and transfer its functional impactto daily life.

In addition, student learning of concepts is one of the challenges facing those in charge of the educational process in the educational field; for example,teaching concepts in a superficial manner to students, and the adoption of teaching methods based on memorization which does not fit with learning concepts. Conceptual learning requires teachers to choose a modern teaching strategy that enables the teacher to discover the wrong concepts among students and to help correct and modify their ideasso that new knowledge is built on a sound and correct scientific basis (Al-Subaie \& AlTurki, 2016).Therefore, this study came to reveal the effect of the teaching strategy based on the KWLH learning schedule on acquiring concepts of scientific research curricula among students of Princess Rahma University College.

\section{Problem}

The current study's problem is focused on the process of students' acquisition of concepts of scientific research curricula during their course of scientific research curricula at Princess Rahma University College / Al-Balqa Applied University and their assimilation of them in a proper manner in light of the researcher's sense of the students'weak acquisition of the concepts and topics and their weak ability to correctly, practically apply the concepts of the academic course. The reason for weak acquisition of the concepts may be due to traditional teaching methods, and to the fact that students are limited to learning the course in a purely theoretical way with the goal of attaining a grade without real understanding or practical scientific application based on linking the terms and concepts of the course to social phenomena and problems. On the other hand, we find that the current educational efforts at the local and global levels are centered ondeveloping real change for the role of both the teacher and the learner in the reality of the educational field as it seeks to make the learner responsible for his learning as a thinker and researcher, so he can link what he learns to his daily life. With these attempts and efforts, it is noted that some teachers focus on covering the textbook without any attention to the quality of teaching and learning outcomes. We desperately need students who have knowledge of what enables them to understand the requirements of the current era, in addition to identifying students who are aware of the problems of their society and are able to make sound decisions in light of the knowledge that they have generated when the teaching 
process is linked to their daily life, where the learner identifies the study problem related to social phenomena and makes assumptions and specifies procedures to explain results and research proposed solutions and recommendations of a research problem.

\subsection{Questions}

Specifically, the study aimed to answer the following main questions:

What is the effect of using the teaching strategy based on the KWLH learning table to acquire concepts of scientific research curricula among Princess Rahma University College students?

In light of the previous main question, the study tried to answer the following sub-questions:

1. Does the degree of acquiring the concepts of scientific research curricula among Princess Rahma University College students differ according to the teaching strategy (teaching strategy based on the KWLH learning schedule and the usual strategy)?

2. Does the degree of acquiring the concepts of scientific research curricula among Princess Rahma University College students differ according to gender (male and female) when teaching both strategies (teaching strategy based on the KWLH learning schedule and the usual strategy)?

3. Is there an effect of the interaction between teaching strategy and gender in acquiring concepts of scientific research curricula among students of Princess Rahma University College?

4. Does the degree of acquiring the concepts of scientific research methods for students of Princess Rahma University College differ according to the cumulative average in the university (excellent, very good, good, acceptable) when teaching them with the two strategies (the teaching strategy based on the KWLH learning schedule and the usual strategy)?

5. Is there an effect of the interaction between the teaching strategy and the university grade point average in acquiring the concepts of scientific research curricula among Princess Rahma University College students?

\subsection{Hypotheses}

1. There is no statistically significant difference $(\alpha=0.05)$ between degrees of acquisition of concepts of scientific research curricula among Princess Rahma University College students due to the teaching strategy (teaching strategy based on the KWLH learning schedule and the usual strategy).

2. There is no statistically significant difference $(\alpha=0.05)$ between degrees of acquisition of concepts of scientific research curricula among students of Princess Rahma University College attributed to gender (male, female) when teaching them both strategies (teaching strategy based on the KWLH learning schedule and the usual strategy).

3. There is no statistically significant effect $(\alpha=0.05)$ between degrees of acquisition of concepts of scientific research curricula among Princess Rahma University College students due to the interaction between teaching strategy and gender.

4. There is no statistically significant difference $(\alpha=0.05)$ between the degrees of acquiring the concepts of scientific research curricula among Princess Rahma University College students due to the university cumulative average when teaching them with two strategies (the teaching strategy based on the KWLH learning schedule and the usual strategy).

5. There is no statistically significant effect $(\alpha=0.05)$ between degrees of acquisition of concepts of scientific research curricula among Princess Rahma University College students due to the interaction between teaching strategy and the GPA. 


\subsection{Procedural Definitions}

\subsubsection{KWLH Learning Schedule-Based Teaching Strategy}

The KWLH Learning Schedule-Based Teaching Strategy is a structured work plan based on four steps: K-what do I know; W- what do I want to know; L- what have I learned; H- how can I learn more. It was developed to achieve specific learning outcomes based on the ideas of structural theory so that it contributes to activating students' thinking about the educational situation and gradually learn the academic topic before new learning takes place so they can build meaning and develop it themselves with the teacher's guidance. KWLH is a teaching strategy based on brainstorming and asking several questions about the learner's previous knowledge, information and experiences related to new learning and what the learner must reach and must know, in the context of providing the type of interaction that occurs during the course of education, whether between the teacher and students or between students with each other under the guidance of the teacher. The goal is to stimulate the thinking processes of students before and during the processes of learning and teaching. They must implement multiple cognitive activities and processes. Use of the KWLH strategy actively contributes to deepening a comprehensive understanding among students as they realize the subject of the first lesson in a way that leads to improving students' performance in the educational situation and achieving learning based on meaning; thus acquiring the desired knowledge for them to improve academic achievement.

\subsubsection{Acquire Concepts of Scientific Research Methods}

Procedurally, it refers to the cognitive ability of the individual and the meaning and understanding of the terminology of scientific research methods and concepts, and his awareness of the contents of these concepts in a theoretical and practical way. Students' acquisition of scientific research concepts in this study was measured by the degree that students obtained on testing the concepts of scientific research methods that were specially prepared for this.

\subsubsection{Cumulative Average (GPA)}

The Cumulative Average (GPA) is an indicator that reflects the student's academic performance and academic achievement in the first university stage to obtain a bachelor's degree. It represents a statistical average of the student's performance in his study of university courses within the study plan for specialization during a specific time period; it may be a semester or what is known as the semester averageand the last cumulative average that indicates the student's rate during the entire school year; in this study, students were classified into four levels according to the cumulative average, which is (excellent, very good, good, acceptable).

\section{Limitations}

The study was conducted within the following limitations:

1. The study was limited to students of Princess Rahma University College - Al-Balqa Applied University - who study the course of scientific research curricula and its statistical methods.

2. The study was limited to a specific study subject, namely: "The problem of the study and its hypotheses" as it was chosen from the approved study plan for the course Scientific Research Methods and Statistical Methods which was developed and reformulated in light of the teaching strategy of the study and its variables. It was taught during the second semester of the academic year 2018/2019.

3. The extent of validity and reliability of the study tool used in collecting study data, which determined the results of the study by the extent of its credibility and stability in general. 


\section{Objectives}

The present study aims to:

1. Identify the effect of using a teaching strategy based on the KWLH learning schedule to improve students' acquisition of scientific research methodology concepts and achieve effective and meaningful learning.

2. Prepare and develop an educational subject according to a teaching strategy based on the KWLH learning schedule and reveal the extent of the effectiveness of this strategy in improving students' acquisition of the concepts of scientific research methods and their ownership of them.

3. The detection of the presence of statistically significant differences between the average scores of the experimental group of students and the mean scores of the students of the control group in testing the concepts of scientific research curricula due to the teaching strategy.

4. Detect the presence of statistically significant differences between the average score of the experimental group of students and the average score of the control group students in examining the concepts of scientific research curricula due to the gender and the university's cumulative average for students and the interaction between teaching strategy, gender, and the cumulative average for students.

\section{Importance of the Study}

The importance of the study is to present educational research that contributes to enriching theoretical literature about acquiring the concepts of scientific research curricula among university students who are studying the course of scientific research curricula using the KWLH learning schedule strategy. The theoretical importance of the study is that it showed thestrategic value of the learning schedule in the educational process and how to achieve desired learning outcomes for the student according to the steps of the strategy and its role in making the learner thefocus in the educational situation with the support of the teacher who acts as a guide for the learner.During the learning and teaching process, the teacher employs the diagnostic evaluation, guidance, and final evaluation within this educational strategy. Through this method they make sure that learning has been achieved, that the student reaches the desired goals, and the student obtains the necessary feedback for improvement and development.

By taking advantage of the results of the current study, the importance from a practical point of view is to direct the attention of teachers of academic courses at the university level toward the effectiveness of the KWLH learning strategy to improve the academic performance of students and enhance the acquisition of concepts and terms of their various courses. In addition, the possibility of employing the learning schedule strategy at grade level will benefit student learning, and that is by taking advantage of the process to apply the KWLH learning schedule strategy in the educational situation and by the teacher and the learner collaborating in a way that clarifies the role of the teacher and the student alike, and enhances student learning based on linking new learning with previous learning and previous experiences and knowledge. This is an essential necessity within the steps of the learning strategy at the beginning and during its implementation when the student is asked what do you know? And what do you want to know? Here, the strategy has worked to develop the student's reading comprehension based on meaning by reorganizing the knowledge and experiences that he previously acquired to fit new concepts, knowledge and information and link them together.

\section{Literature Review}

While reviewing the theoretical framework of the study, several previous studies related to the 
teaching strategy based on the KWLH learning table and the concepts of scientific research methods emerged and have been arranged in chronological order starting with the most recent, as follows:

\subsection{Related Studies: Teaching Strategy Based on the KWLH Learning Schedule}

The aim of Woyengibarakemi Soinyoand Brown (2019) was to examine the effects of Know-WantLearn (KWL) differentiation and Jigsaw Cooperative Learning (JCL) strategies on the performance of Social Studies students at the Junior Secondary School (JSS) level in Port Harcourt Local Government Area of Rivers State.The study involved three groups which were two experimental groups (KWL) differentiation learning strategy and (JCL) strategy and a control group taught with traditional learning strategy, and the sample consisted of 177 (90 male students and 87 female students). The findings of the study showed that (KWL) differentiation and (JCL) strategies could improve the performance of junior secondary school students in Social Studies. But the interaction effect of (KWL) differentiation, (JCL) strategies and gender on students' performance in Social Studies was not significant.

The objectives of the research of Kusumaningrum and Widiyanto (2018) was to find the effects of using KWL strategy on students' reading skills, and to find out the significant difference on the students' reading skills taught by using KWL strategy and taught without using KWL strategy. The samples of the study were grouped as an experimental class which consisted of 32 , and a control class which consisted of 32 students from the eighth grade in SMP N 1 Pecangaan Jepara in the academic year 2017/2018. The results showed that the students' reading skills taught by using KWL strategy were good, and the difference between the students' reading skill taught with and without using KWL strategy was significant. It means that the students taught by using KWL strategy learned more than the students taught without using KWL strategy.

The Bou Aisha (2018) study sought to identify the impact of using the KWL strategy in teaching a computer course on developing academic achievement for first-year high school students in Dhahran, Saudi Arabia. The semi-experimental approach was used to achieve the objectives of the study, as the study sample consisted of (27) students divided into two groups: the experimental group (14) students were taught by the KWL strategy, and the control group (13) students were taught in the usual way. The results of the study showed that there were statistically significant differences in academic achievement attributable to the teaching strategy, which was in favor of the experimental group.

The aim of Alsoudi study (2017) is to examine the effect of using the KWL strategy on acquiring religious concepts among eighth graders in Jordan. The sample of the study consisted of 139 male and female students (4 groups); they were chosen randomly from the Education Directorate in Tafila. Two sections formed the experimental group (one section for males and one section for females) were taught using the KWL strategy, and the other two sections formed the control group (one section for males and one section for females) and they were taught using the regular teaching strategy, and the results indicated that there is a statistically significant difference in achievement which is in favor of experimental group, and there were no statistically significant differences in achievement attributable to gender or to the interaction between gender and teaching strategy.

The aim of Zouhor, Bogdanović, Skuban and Pavkov-Hrvojević research (2017) was to examine the effect of the mKWL strategy on primary school students' achievement in physics. Quasi experimental research was carried out with 110 sixth-grade students divided into an experimental and a control group. The students in the experimental group were taught using TQHL charts which based on mKWL strategy and the students in the control group were taught using direct teaching. The results showed that mKWL strategy in a sixth-grade physics class has a positive effect on students' achievement, and it can be suggested to implement the described strategy in teaching physics in order to improve students' achievement in this subject.

The objective of Mardiana's (2016) studywas to investigate the influence of KWL strategy toward students' reading comprehension achievement and five aspects of characters which are motivating 
oneself, self-awareness, managing emotion, empathy, and social skills. The study sample consisted of Seventy four seventh graders equally divided into experimental $(\mathrm{N}=37)$ and control groups $(\mathrm{N}=37)$. The result showed that there was significant improvement in students' reading comprehension achievement, where the experimental group outperformed in reading comprehension, and the result showed improvement on students' characters and there were also found difference in each aspect of character after they were taught by using KWL strategy.

Al-Balawi (2016) conducted a study aimed at revealing the effect of teaching using the KWL strategy on the achievement of students of theoretical specializations at the Faculty of Arts and Sciences in Al-Ula in the course of statistical applications in the humanities, as the use of the experimental curriculum worked on a sample of (44) students. The study concluded that there were statistically significant differences between the pre and post application of the achievement test of the experimental group and it is in favor of the post application, as it was found that there are statistically significant differences between the students of the experimental group and the control in the post application of the achievement test which is in favor of the experimental group.

Al-Subaie and Al-Turki (2016) attempted to reveal the effectiveness of teaching by using KWL in correcting wrong-understanding patterns in some concepts of the computer course for first-year high school students, where the study was applied to a sample of (6o) students distributed to two groups represented by the experimental group and the control group, The study concluded that there are statistically significant differences between the pre and post application of the test related to correcting wrong-understanding patterns of the concepts mentioned in the unit "Programming in Visual Basic Studio" at the experimental group and it is in favor of the post application, as it also shows the presence of statistically significant differences between students of the experimental group and the control group in the post application of a test for the experimental group.

The study of Al-Alawin and Al-Ayasrah (2016) aimed to investigate the impact of a teaching strategy that integrates the KWL strategy and the POE strategy in developing environmental concepts among ninth grade students and developing their attitudes towards the environment. The sample of the study consisted of (99) male and female students from the schools of Hosni Fariz for boys and Aisha bint Abi Bakr for girls, affiliated to the Directorate of Education in Al Balqa governorate. The results indicated a statistically significant effect attributed to the combined strategy on acquiring environmental concepts among students and developing their attitudes toward the environment, as well as having a statistically significant effect attributed to the interaction between the integrated strategy and gender in developing environmental trends, while the results showed that there was no statistically significant effect due to the interaction between the integrated strategy and gender in acquiring environmental concepts.

The study of Al-Otaibi (2015) sought to reveal the effectiveness of the KWLH teaching strategy in teaching the prophetic biography on developing moral values and awareness of them among primary school students. The study was applied to (40) sixth-grade students according to the experimental approach, and the results have shown the effectiveness of the KWLH teaching strategy in the development of moral values and the development of awareness of moral values among students of the experimental group, in addition to a correlation between commitment to and awareness of moral values.

The objective of the studyby Riswanto, Risnawati, and Lismayanti (2014) was to see whether the use of KWL (Know, Want, and Learned) strategy was effective in improving students' reading comprehension achievement in learning English as a Foreign Language. The population was the eighth grade students of SMPN 4 Palembang in academic year of 2011/2012 with a total number of 254 students. Forty students were taken as sample. There were two groups (experimental and control groups), each of which consisted of 20 students. The data were collected by using a multiple choice reading comprehension test. The results showed that the KWL strategy was effective in improving the students' reading comprehension achievement. The effectiveness of the contribution of KWL strategy on students' reading comprehension achievement was $70.5 \%$.

The purpose of the study by Hamdan (2014) is to examine the effectiveness of the KWL-Plus 
strategy on the performance of Jordanian Tenth Grade male students in reading comprehension. The sample of the study was selected from a private school and a public school. All the public school students represented the experimental group who were taught reading with the KWL-Plus strategy. Whereas, the private school students represented the control group who were taught with conventional reading strategies. To collect the data, the pre-test was conducted prior to the application of the strategy, and the post-test was given to the students in the two groups after the application of the strategy. The results indicated that the experimental group of the public school scored higher on the reading comprehension post-tests than their peers did in the control group, and the KWL-Plus strategy was effective in improving the reading comprehension performance.

Muhammad (2013) conducted a study aimed at investigating the impact of the use of the KWL strategy in teaching mathematics on academic achievement for sixth-graders in Sharjah. The sample of the study consisted of (104) male and female students, distributed into four groups: two groups for male experimental and control (50) students, and two groups for female experimental and control (54) students. The study concluded that there are statistically significant differences in the academic achievement of male and female students due to the method of teaching, which benefited the students who studied the KWL strategy, and the presence of statistically significant differences in the academic achievement of male and female students due to gender, which is in favor of females.

Aram's (2012) study attempted to know the effect of using the KWL strategy in acquiring concepts and critical thinking skills for seventh graders, where the study was applied to a sample of (97) female students using the experimental approach. The results showed that there are statistically significant differences between the mean scores of the experimental group and the control group in scientific concepts tests and critical thinking skills tests for the experimental group.

\subsection{Comment on Previous Studies}

In light of the foregoing, it was noted that previous studies focused on addressing the strategy of the KWL learning schedule within three phases, while others dealt with the strategy of the KWLH learning schedule within four phases. Through its use as a teaching strategy, it represented the main independent variable in the study which examined its impact whether in academic achievement, developing trends, or acquiring concepts in courses of study. Most ofthe studies relied on the experimental approach in their design. This is what the current study likened to previous studies as it sought to investigate the impact of the teaching strategy based on the KWLH self-learning schedule in acquiring the concepts of scientific research methods for students of Princess Rahma University College, and by adopting the quasi-experimental approach to study design and application.

The current study differed in the nature and number of variables that it addressed, namely: the gender and the cumulative average of a student at the university level. It examined the data of the impact of the teaching strategy based on the learning schedule KWLH in acquiring concepts of scientific research methods for students of Princess Rahma University College in light of gender variables and the university grade point average. It also studied the effect of the interaction between the KWLH strategy and gender, and the effect of the interaction between the KWLH strategy and the grade point average on the acquisition of concepts of scientific research curricula among students. In this context, the present study was distinguished in that it applied the study to students studying the course of scientific research curricula, which is a compulsory college requirement for students in various specializations at Princess Rahma University College / Al-Balqa Applied University.

\section{Methods}

The quasi-experimental design approach was used in this study to investigate the effect of using the teaching strategy based on the KWLH learning schedule to help students acquire the concepts of scientific research curricula in light of gender variables and the university's cumulative average for Princess Rahma University College students. 


\subsection{Community and Study Sample Participants}

The study population consisted of four divisions studying the research methodology course and its statistical methods at Princess Rahma University College / Al-Balqa Applied University, who were studyingduring the second semester of the academic year 2018/2019. Two divisions were deliberately chosen due to the interest of the course teachers in the subject matter of the study, the nature of the timeline, and the number of members of the two divisions appropriate to conduct the experiment with its conditions. In light of this, they were randomly assigned and assigned to two groups: the first group (the experimental group) was taught using the KWLH strategy. There were (42) male and female students in the experimental group. The second group (the control group) was taught in the usual way and the number of students were (45) male and female students.

Students in both groups (experimental and control) were classified according to gender into two sections (male, female) and according to the university grade point average (excellent, very good, good, and acceptable), and Table 1 shows the distribution of the sample members according to group, gender, and university grade point average.

Table 1: Distribution of Study Personnel According to Group, Gender and Grade Point Average.

\begin{tabular}{|c|c|c|c|c|c|c|c|}
\hline${\mathrm{C} / \mathrm{A}^{*}}^{-}$Group & $\begin{array}{c}\text { Experimental } \\
\text { Group }\end{array}$ & $\begin{array}{c}\text { Control } \\
\text { Group }\end{array}$ & Total & Group & $\begin{array}{c}\text { Experimental } \\
\text { Group }\end{array}$ & $\begin{array}{c}\text { Cont } \\
\text { ol Group }\end{array}$ & Total \\
\hline Excellent & 5 & 9 & 14 & \multirow{2}{*}{ Male } & \multirow{2}{*}{17} & \multirow{2}{*}{20} & \multirow{2}{*}{37} \\
\hline Very Good & 13 & 12 & 25 & & & & \\
\hline Good & 15 & 14 & 29 & \multirow{2}{*}{ Female } & \multirow{2}{*}{25} & \multirow{2}{*}{25} & \multirow{2}{*}{50} \\
\hline Acceptable & 9 & 10 & 19 & & & & \\
\hline Total & 42 & 45 & 87 & Total & 42 & 45 & 87 \\
\hline
\end{tabular}

${ }^{*}$ Cumulative Average

\subsection{Tools}

To answer the study questions, the study used the following tools:

\subsubsection{Testing the Concepts of Scientific Research Methods}

\subsubsection{Validity and Reliability of the Test}

The scientific research curriculum concepts test, which was prepared and developed in the light of perusal of the previous relevant literature, was adopted according to the pattern of objective tests where the test consisted of (30) paragraphs of multiple choice so that the student was given one degree on the correct answer and zero on wrong answer. The score range on the test reached (o-3o) points.

To find the trustworthiness of the tool, it was presented to three arbitrators who are specialists and experienced in teaching courses of scientific research curricula, and they were asked to give an opinion on the test paragraphs in terms of formulating the paragraphs and the degree of their suitability for the objectives of the study where some of the paragraphs were deleted and added so that the tool was in its final form. It consisted of (30) items.

To ensure the consistency of the study tool, it was verified in two ways. First, the test application and the re-application of the test-stability with a two-week interval on a survey sample from a study community other than the study sample consisted of (18) students to verify the stability of the test and its consistency over time, and by applying the Pearson Correlation Coefficient, the test stability coefficient was calculated and it was found equal to (o.841) which is a suitable stability factor to achieve the purposes of the study. As for the second method, it was accomplished using the Kuder- 
Richardson KR2o formula to find the internal consistency where the test stability coefficient reached (o.89), which indicates the stability of the study tool, and indicates that the test has an appropriate degree of stability and internal consistency.

\subsubsection{Educational Scientific Article}

The subjects of the study unit and its title (the problem of the study and its hypotheses) contained in the study plan for the research curriculum course and its statistical methods were prepared as follows: Definition of the concept of the study problem, considerations for choosing the research problem, sources for obtaining research problems, study hypotheses, concept of hypothesis, sources of obtaining hypotheses, conditions for formulating hypotheses, types of hypotheses, judgment on zero hypothesis, and errors related to statistical hypotheses. The procedures that were used in teaching the subjects of the unit (the study problem and its hypotheses) according to KWLH strategic steps were as follows:

- These topics were presented to students in line with the objectives of the KWLH teaching strategy and procedures in a manner that reveals the ability of the teaching strategy and its effectiveness in achieving the desired effective learning among students of the study sample.

- Students were introduced to the KWLH learning schedule strategy, their role during the implementation of the strategy, and were trained on what to follow when filling in the columns for the learning schedule distributed to students.

- During the implementation phase of the strategy, the division of students into cooperative groups and the activation of brainstorming, dialogue and discussion was taken into consideration in order to stimulate the previous knowledge of the student (what do I know).

- Beginning to address topics for the unit of study by presenting the main ideas, students discussing what they know about them, identifying perceptions about concepts, and recording information in the first column $(\mathrm{K})$.

- Asking the student about these ideas related to the concepts of the lesson and what he wants to know about it, taking into account the application of brainstorming conditions and recording them in the second column $(\mathrm{W})$.

- Begin explaining the lesson in the light of employing effective dialogue, discussion and communication, taking into account correcting concepts and wrong perceptions, if any, for the student and deepening the understanding of the ideas and concepts mentioned in the lesson.

- Provide immediate feedback to support the correct answers and correct the wrong ones with the aim of improving understanding and understanding of the lesson ideas.

- After explaining the ideas of the lesson, the student was asked what he learned and to compare what he learned (L) with what he wanted to learn (W) i.e. comparing the goals with the achievements, then he compared what he (L) learned with what the student scored in the first column $(\mathrm{K})$ in a way that reinforced the correct concept and modified the wrong concept.

- Directing the student toward learning resources to enhance how the student can learn more $(\mathrm{H})$ by looking at additional learning resources, proposing applications for realistic research problems, addressing them according to the concepts and ideas contained in each lesson, training the student in a more practical way to the ideas mentioned in each lesson, and reviewing research studies published on the internet.

\subsection{Procedures}

During this study, the following steps were taken:

1. Review the literature and previous studies related to the KWLH-based teaching strategy and curricula of scientific research, prepare the study tool "Test Concepts of Scientific Research 
Approaches" and find reliability and consistency thereof.

2. After determining the study community and intentionally selecting the sample from the Princess Rahma University College, the teaching strategy was applied to the members of the study sample in the second semester of the academic year 2018/2019 with the help of some of the course teachers after the pre-test of the experimental and control group was applied. Students of the experimental group were informed about the academic topic in each lecture and distributed the KWLH teaching strategy chart, which required each learner to complete it before and during the explanation of the topic according to the steps of the strategy in a way that makes each learner define information and previous knowledge $(\mathrm{K})$ relevant to the subject of the new lesson, what he wanted to know, what he learned, and how he could learn more. In the context of the educational situation, each learner compared what he actually learned (L) with what knowledge he wanted to know (W) toreview achievements, amend wrong information, and identify unanswered questions. Students were directed to search for the answersand obtain additional information from various learning sources $(\mathrm{H})$.

3. After determining the study community and intentionally selecting the sample members from Princess Rahma University College, a test of concepts of the post-scientific research curricula was applied to the members of the study sample in the second semester of the academic year 2018/2019 with the help of some of the course teachers.

4. The collected statistical data for the study sample individuals were classified in the study variables: gender, and the university grade point average.

5. Raw statistical data was entered into the computer and a statistical SPSS package was conducted to find the descriptive and inferential statistics required according to the study design, its variables, and the appropriate statistical treatments.

\subsection{Design}

The researcher used the quasi experimental design in this study considering the following variables:

1. Independent variables:

- Teaching strategy, and it has two levels:

1. KWLH Learning Table-Based Teaching Strategy.

2. The usual strategy.

- Gender, which is a classification variable (secondary) has two levels:

1. Male.

2. Female

- The university grade point average, which is a (secondary) classification variable that has four levels:

1. Excellent

2. Very good

3. Good

4. Acceptable

2. The dependent variable:

- It includes one variable, which is:

1. Acquire concepts of scientific research methods.

\subsection{Statistical Processing}

After applying the experimental treatment, the study questions were answered using descriptive statistics (calculated averages, standard deviations) and inferential statistics through the use of the associated two-way analysis (ANCOVA) with global design $(2 \times 2)$ and global design $(2 \times 4)$ for student results in the two groups (experimental and control) on the dependent study variable, which 
is the acquisition of concepts of scientific research methods, and the test of the significance of the difference at the level of statistical significance $(\alpha=0.05)$ in the light of the gender variables and the university cumulative average for students of the study sample. The eta square $\left(\eta^{2}\right)$ was used to know the effect size and consequently to know the effect of the teaching strategy KWL, and the ratio of the explained variance (predicted) in the dependent variable, which is the acquisition of concepts of scientific research curricula among students of Princess Rahma University College.

\section{Results}

Results related to the first question, which states: Does the degree of acquisition of concepts of scientific research methods differ for Princess Rahma University College students according to the different teaching strategy (teaching strategy based on the KWLH learning schedule and the usual strategy)?

To answer the first study question, calculated averages and standard deviations were extracted for the performance of students, members of the study sample, on testing the concepts of pre and post scientific research curricula and Table 2 illustrates this.

Table 2: Mathematical Averages and Standard Deviations of Student Performance by Individuals of the Study Sample on Test Concepts of Pre and Post Scientific Research Methods by Teaching and Gender Strategy.

\begin{tabular}{|c|c|c|c|c|c|c|}
\hline \multirow{3}{*}{ Group } & & & \multicolumn{2}{|c|}{ Pre-Test } & \multicolumn{2}{c|}{ Post-Test } \\
\cline { 3 - 8 } & Gender & Numbers & Calculated Mean & Standard Deviation & Calculated Mean & Standard Deviation \\
\hline \multirow{3}{*}{ Experimental } & Males & 17 & 10.59 & 3.97 & 21.71 & 4.47 \\
\cline { 2 - 7 } & Females & 25 & 10.48 & 3.89 & 21.28 & 4.04 \\
\cline { 2 - 7 } & Total & 42 & 10.52 & 3.87 & 21.45 & 4.17 \\
\hline \multirow{3}{*}{ Control } & Males & 20 & 9.80 & 3.74 & 16.30 & 5.58 \\
\cline { 2 - 8 } & Females & 25 & 10.20 & 4.50 & 15.84 & 6.53 \\
\cline { 2 - 7 } & Total & 45 & 10.02 & 4.14 & 16.04 & 6.06 \\
\hline \multirow{3}{*}{ Total } & Males & 37 & 10.16 & 3.81 & 18.78 & 5.73 \\
\cline { 2 - 7 } & Females & 50 & 10.34 & 4.16 & 18.56 & 6.03 \\
\cline { 2 - 7 } & Total & 87 & 10.26 & 4.00 & 18.66 & 5.87 \\
\hline
\end{tabular}

The mean for the achievement of male students in the experimental group on the post-test was (21.71) with a standard deviation of (4.47), while for the girls it was (21.28) and with a standard deviation (4.04). The mean score for the achievement of male students of the male control group on the posttest was (16.30) with a standard deviation of (5.58). While for female students it was (15.84) with a standard deviation of (6.53).

From the above, it is clear that there are apparent differences in favor of the male experimental group. To test the significance of the differences between the averages of the post-achievement of the two groups (experimental and controlling) and gender (male, female), and the interaction between the group and gender and test the validity of zero hypotheses, the two-factor analysis of co-variability (ANCOVA) with factor design (2X2), and Table 3 illustrates the results.

Table 3: The Results of the ANCOVA Associated Performance of Students of the Study Sample on Testing the Concepts of Scientific Research Methods for the Experimental and GenderControl Groups.

\begin{tabular}{|l|c|c|c|c|c|}
\hline Sourceof Variance & $\begin{array}{c}\text { Sum of } \\
\text { Squares }\end{array}$ & $\begin{array}{c}\text { Degree of } \\
\text { Freedom }\end{array}$ & $\begin{array}{c}\text { Average of } \\
\text { Squares }\end{array}$ & $\begin{array}{c}\text { Calculated } \\
\text { Value }\end{array}$ & $\begin{array}{c}\text { Statistical } \\
\text { Significance }\end{array}$ \\
\hline Pre-Test Companion & 1975.803 & 1 & 1975.803 & 462.471 & $0^{* 000}$ \\
\hline Teaching Strategy & 481.978 & 1 & 481.978 & 112.815 & $0^{*}$ \\
\hline Gender & 8.099 & 1 & 8.099 & 1.896 & 0.172 \\
\hline
\end{tabular}




\begin{tabular}{|l|c|c|c|c|c|}
\hline Sourceof Variance & $\begin{array}{c}\text { Sum of } \\
\text { Squares }\end{array}$ & $\begin{array}{c}\text { Degree of } \\
\text { Freedom }\end{array}$ & $\begin{array}{c}\text { Average of } \\
\text { Squares }\end{array}$ & $\begin{array}{c}\text { Calculated } \\
\text { Value }\end{array}$ & $\begin{array}{c}\text { Statistical } \\
\text { Significance }\end{array}$ \\
\hline Teaching Strategy - Gender & $\mathbf{2 . 2 0 4}$ & $\mathbf{1}$ & $\mathbf{2 . 2 0 4}$ & $\mathbf{0 . 5 1 6}$ & 0.475 \\
\hline Error & 350.326 & 82 & 4.272 & & \\
\hline Adjusted Total & 2965.655 & 86 & & & \\
\hline
\end{tabular}

The results of the accompanying binary variance analysis indicate that there is a statistically significant effect at the level of $(\alpha=0.05)$ of the teaching strategy, where the calculated value of $(F)$ (112.815) and its statistical significance are less than (0.05), and by reference to the calculated averages shown in Table 2 we find that it is in the interest of the members of the experimental group, in addition to what the results of the adjusted calculated means of the experimental and control groups indicated in the light of the gender variable shown in Table 4. (21.16), while the mean was calculated for the control group (16.38), in addition to the average calculated mean for the achievement of male experimental group students was (21.316) and with a standard error (0.502), while for females (21.021) and with a standard error (o.414), on the other hand, the mean calculated achievement of the group's students Male control (16.859) with a standard error (0.463), while for females (15.917) and with a standard error (0.413), meaning that the differences are in favor of the members of the experimental group.

Table 4: (Modified) Calculated Averages and Standard Errors of Student Performance on the Acquisition of Scientific Research Curriculum Concepts by Group and Gender.

\begin{tabular}{|l|l|c|c|c|}
\hline Group & Gender & Number & Modified Calculated Average & Standard Error \\
\hline \multirow{4}{*}{ Experimental } & Male & 17 & $\mathbf{2 1 . 3 1 6}$ & $\mathbf{0 . 5 0 2}$ \\
\cline { 2 - 5 } & Female & $\mathbf{2 5}$ & $\mathbf{2 1 . 0 2 1}$ & $\mathbf{0 . 4 1 4}$ \\
\cline { 2 - 5 } & Combined & $\mathbf{4 2}$ & $\mathbf{2 1 . 1 6 8}$ & $\mathbf{0 . 3 2 5}$ \\
\hline \multirow{3}{*}{ Control } & Male & $\mathbf{2 0}$ & 16.859 & 0.463 \\
\cline { 2 - 5 } & Female & $\mathbf{2 5}$ & 15.917 & 0.413 \\
\cline { 2 - 5 } & Combined & 45 & 16.388 & 0.310 \\
\hline \multirow{3}{*}{ Total } & Male & 37 & 19.087 & 0.341 \\
\cline { 2 - 5 } & Female & 50 & 18.469 & 0.292 \\
\cline { 2 - 5 } & Combined & 87 & 18.778 & 0.225 \\
\hline
\end{tabular}

Table 5: Eta SquareValues and the Explanation of the Contrast Ratio for the Performance of Students, Members of the Study Sample, on Testing the Acquisition of Concepts of Scientific Research Curricula According to Teaching and Gender Strategy.

\begin{tabular}{|l|c|c|c|c|}
\hline Source of Variance & Sum of Squares & ETA Squared & Percentage Variance Explanation & Effect Size \\
\hline Companion Pre-test & 1975.803 & 0.666 & $66.62 \%$ & \\
\hline Teaching Strategy & 481.978 & 0.1624 & $16.24 \%$ & Large \\
\hline Gender & 8.099 & 0.0027 & $0.27 \%$ & Small \\
\hline Teaching Strategy * Gender & 2.204 & 0.0007 & $0.07 \%$ & Small \\
\hline Error & 350.326 & & & \\
\hline Adjusted Total & 2965.655 & & & \\
\hline
\end{tabular}

It is clear from Table 5 that the teaching strategy has caused a great difference in the acquisition of concepts of scientific research curricula among students of the study sample, and by using the eta square $\left(\eta^{2}\right)$ it was found to be equal to (o.1624) and this means that the teaching strategy has made a great difference in improving students' acquisition of the concepts of scientific curricula and their awareness of them (dependent variable) and thus it explains (16.24\%) of the total variation in the acquisition of concepts of scientific research methods among the members of the study sample, and that this variation is attributed to the teaching strategy (teaching strategy KWLH learning schedule) 
and this result corresponds to the results of the study (Woyengibarakemi Soinyo \& Brown, 2019) and the study of Kusumaningrum and Widiyanto (2018) and the study (Alsoudi, 2017) and the study of Bou Aisha (2018) and the Aram study (2012), and to explain this perhaps the reasons behind the success and effectiveness of this teaching strategy lies in teaching the usual strategy as follows:

- Building the educational material (scientific knowledge) in an approach that considers the characteristics of students and their mental capabilities, the individual differences between them, and the previous knowledge that they possess.

- This teaching strategy is based on the principle of observing the speed of self-learning among students.

- This teaching strategy seeks to attract the attention, interest, and motivation of students toward learning.

- This teaching strategy includes implicit teaching methods that can be employed during the application of the KWLH strategy, for example brainstorming, dialogue, discussion, and collaborative learning. It is a reason that has positive effectiveness in improving students' performance and learning as they involve students in the educational process, and thus the success of the teaching strategy KWLH.

Results related to the second question, which states: Does the degree of acquiring the concepts of scientific research curricula among Princess Rahma University College students differ according to gender (male and female) when teaching both strategies (teaching strategy based on the KWLH learning schedule and the usual strategy)?

Referring to Table 2, there was an apparent difference between the calculated averages of students'scores on testing the concepts of scientific research methods in the experimental and control groups by gender (male, female), as the calculated mean for female students in the experimental group reached (21.28), while the calculated mean for the scores of male students in the experimental group were (21.71). On the other hand, the mean for the scores of female students in the control group was (15.84), while the mean for the scores of male students in the same group was (16.30).

To test the significance of the apparent differences between the calculated averages of the postperformance on testing the concepts of scientific research methods according to the gender variable (male, female), the co-variable analysis (ANCOVA) with a global design (2 $\left.\mathrm{X}_{2}\right)$ was used. As demonstrated in Table 3, the results of the analysis indicated the absence of a statistically significant difference. This was attributed to the gender variable between the averages of the students'scores for the study sample members in both groups (experimental and control) on testing the concepts of scientific research approaches at the level of significance $(\alpha=0.05)$ where the calculated value of $(F)$ (1.896) The statistical significance for it (o.172), given the modified calculated averages in Table 4, we find that they were in the experimental group for the benefit of male students, as the calculated mean of their postgraduate degrees in the experimental group on testing the concepts of scientific research approaches a score of (21.31), while the post-mean calculated average for female students in the experimental group on the same test was (21.02). On the other hand, the overall average for the scores of male students in the control group on the same test was (16.85) points, while the overall average for female students in the control group on the same test reached (15.91) points. In addition, it is clear from Table 5 that the gender variable has caused a small variation in the acquisition of concepts of scientific research methods and their learning among students of the study sample, because the size of the effect of the gender variable in the concepts of scientific research methods (the dependent variable) was small, and using the etasquare $\left(\eta^{2}\right)$ was found to be equal to (o.0027); therefore, it explains $(0.27 \%)$ of the total variance in learning the concepts of scientific research methods for students of the study sample and this result corresponds to the results of the study (Kusumaningrum \& Widiyanto, 2018) and the study (Alsoudi, 2017), but it is not consistent with Muhammad's study (2013).

This result demonstrates that the improvement of students 'performance in acquiring concepts 
of scientific research methods is primarily due to the teaching strategy KWLH learning schedule and its effectiveness in improving student learning. This is by virtue of the fact that it has been able to employ students' knowledge and information and their previous experiences in preparing to interact with new learning topics and determine what they want to learn in the course and their awareness of the objectives of the educational tasks desired to be achieved according to the perspective of this KWLH strategy. The nature of the educational material in the teaching strategy was presented in a manner that suits the educational stage and the characteristics of the target group (learners) whether for males or females in the experimental group who participated in the study related social reality of life for all students, and this may be an important factor, as research issues and problems related to social phenomena have been addressed, which have contributed to an increase in students' motivation towards learning.

Results related to the third question which states: Is there an effect of the interaction between teaching strategy and gender in acquiring concepts of scientific research curricula among students of Princess Rahma University College?

To answer this question, the calculated mean and the standard deviation of students'grades were extracted on a test of the degree of students' acquisition of scientific research concepts, and by testing the significance of the apparent differences between the calculated means of postperformance on the test for the two groups (experimental and control) according to the gender variable (male, female), and the interaction between a teaching strategy and gender using the associated dual-contrast analysis (ANCOVA) with a global design ( $\left.2 \mathrm{X}_{2}\right)$, as shown in Table 3. The results shown in Table zindicated that there was no statistically significant effect of the interaction between the teaching and gender strategy at the level of indication $(0.05=\alpha)$, where the calculated value of (F) reached (0.516) and its statistical significance was higher than the value (0.05) which reached (0.47) which is a statistically insignificant value. This result is consistent with the result of a study (Alsoudi, 2017) and the study of Alawin and Ayasrah (2016). To find the effect of the interaction between the teaching strategy and gender in acquiring the concepts of scientific research methods, the effect size was found using the eta square $\left(\eta^{2}\right)$ and the ratio of the variance (prediction) explained as shown in Table 5, which shows that the size of the interaction effect was small, as it was found that it is equal to (0.0007) which is a small effect size. This means that the magnitude of the effect of the interaction between the teaching strategy and gender has brought about a small variation in the acquisition of the concepts of scientific research curricula (dependent variable) and thus it explains $(0.07 \%)$ of the total variation in the acquisition of the concepts of scientific research methods among students of the study sample. It is evident from Figure 1 that performance of male and female students in the experimental group that studied with the teaching strategy KWLH was better than the performance of students in the control group that studied with the usual strategy. The results are in favor of the experimental group; this means that the two variables work independently of each other in the field of acquiring concepts of scientific research curricula and that the effect is due to the teaching strategy in the first place, as the effect of the KWLH teaching strategy was equal on the students of the experimental group, both males and females in acquiring the concepts of scientific research curricula. Both males and females interacted with the educational learning situation in the context of employing the teaching strategy KWLH and thus improving the performance of male and female students in the post-test. This is indicated by the calculated averages shown in Tables 2 and 4 , as all students of the study sample (male and female students) seek to improve their academic achievement and achieve meaningful learning.Their acquisition of knowledge and information is evident by comparing the results of the students of the study sample members on the pre and posttest, for example, what was found in the results of the members of the experimental group, as the calculated mean for the achievement of post-male students on the test reached (21.71) points compared to the pre-test which reached (10.59) points. As for the calculated mean, the students'postachievement score on the test reached (21.28) points compared to the pre-test which reached (10.48) points. Here we see that the effect of the teaching strategy exists and is apparent on male and female students who are members of the experimental group. Likewise, for the control group, there was an 
improvement in the performance of both males and females when comparing the results of the pre and post-test of the male and female group members, but the results in this study came in favor of the experimental group that studied the KWLH strategy where their achievement and performance were better than that of the control group.

All of this indicates that the KWLH teaching strategy is more effective and positive in student learning, improving their knowledge and understanding of the concepts of scientific research and motivating the learner to build his knowledge and information internally and in the context of being affected by the surrounding environment and interacting with it. This occurs given the consideration of individual differences between learners and that each learner has a method and specificity in understanding the information and dealing with it, even if the size of the effect of the interaction between the teaching and gender strategy in acquiring the concepts of scientific research methods is small. It creates a small variation in its acquisition (the dependent variable) and thus explained $(0.07 \%)$ of the total variation in the acquisition of the concepts of the scientific research curricula necessary to learn the steps of scientific research and perfect the skills among students (members of the study sample) of Princess Rahma University College. Figure 1 illustrates.

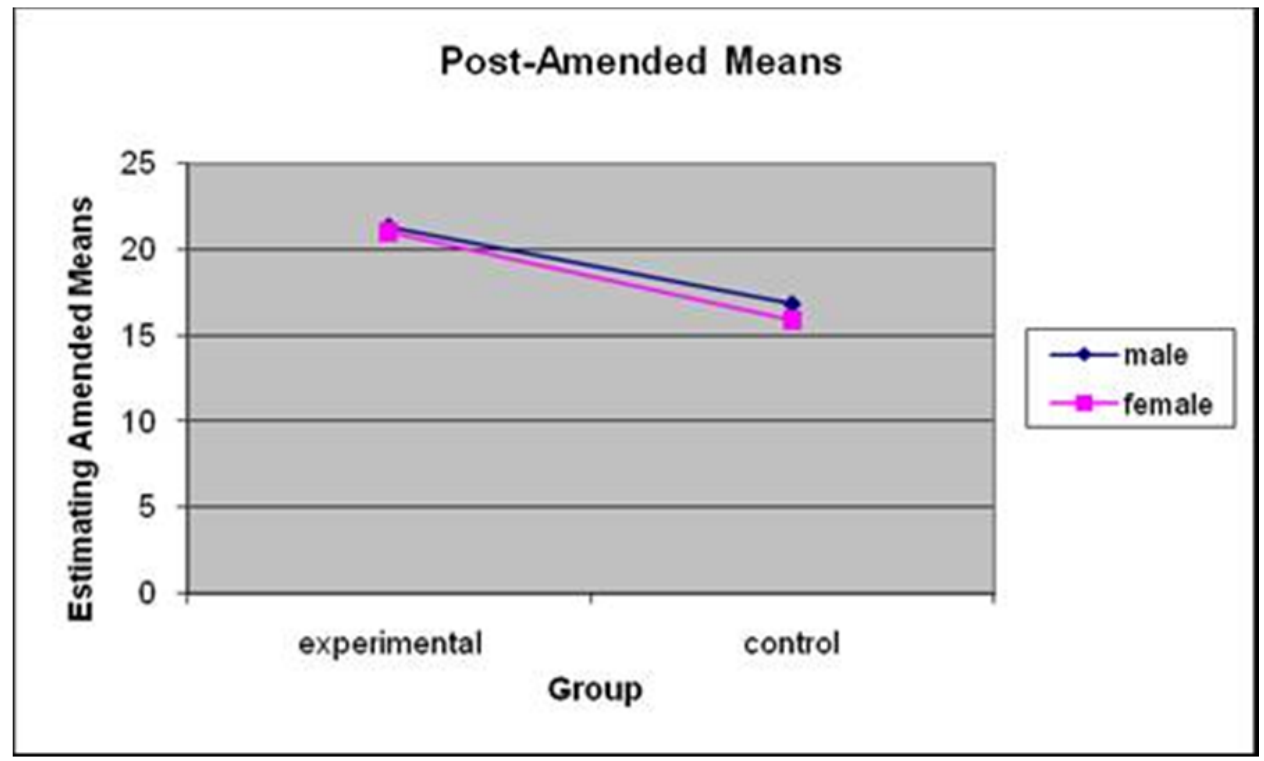

Figure 1: Absence of the Interaction Between Teaching Strategy and Gender in Acquiring Concepts of Scientific Research Methods.

Results related to the fourth question, which states: Does the degree of acquisition of the concepts of scientific research curricula among students of Princess Rahma University College differ according to the cumulative average in the university (excellent, very good, good, acceptable) when teaching them in the two strategies (the teaching strategy based on the KWLH learning schedule and the usual strategy )?

To answer the fourth study question, calculated averages and standard deviations for students' performance were extracted from the study sample on testing the concepts of pre and post scientific research curricula and Table 6 illustrates this. 
Table 6: Mathematical Averages and Standard Deviations of Student Performance of Individuals of the Study Sample on Test Concepts of Pre and Post Scientific Research Methods According to Teaching Strategy and University GPA

\begin{tabular}{|c|c|c|c|c|c|c|}
\hline \multirow[b]{2}{*}{ Group } & \multirow[b]{2}{*}{$\begin{array}{l}\text { Cumulative } \\
\text { Average }\end{array}$} & \multirow[b]{2}{*}{ Number } & \multicolumn{2}{|c|}{ Pre-test } & \multicolumn{2}{|c|}{ Post-test } \\
\hline & & & $\begin{array}{c}\text { Calculated } \\
\text { Average } \\
\end{array}$ & $\begin{array}{c}\text { Standard } \\
\text { Deviation }\end{array}$ & $\begin{array}{c}\text { Calculated } \\
\text { Average }\end{array}$ & $\begin{array}{c}\text { Standard } \\
\text { Deviation }\end{array}$ \\
\hline \multirow{5}{*}{ Experimental } & Excellent & 5 & 17.20 & 1.79 & 27.80 & 2.39 \\
\hline & Very Good & 13 & 12.77 & 1.59 & 24.15 & 1.91 \\
\hline & Good & 15 & 9.27 & 1.39 & 20.13 & 1.92 \\
\hline & Acceptable & 9 & 5.67 & 1.58 & 16.22 & 1.79 \\
\hline & Total & 42 & $10.5^{2}$ & 3.87 & 21.45 & 4.17 \\
\hline \multirow{5}{*}{ Control } & Excellent & 9 & 15.67 & 1.73 & 23.89 & 3.02 \\
\hline & Very Good & 12 & 11.50 & 2.32 & 18.50 & 3.48 \\
\hline & Good & 14 & 9.14 & 1.17 & 13.93 & 4.03 \\
\hline & Acceptable & 10 & 4.40 & 1.17 & 9.00 & 1.33 \\
\hline & Total & 45 & 10.02 & 4.14 & 16.04 & 6.06 \\
\hline \multirow{5}{*}{ Total } & Excellent & 14 & 16.21 & 1.85 & 25.29 & 3.34 \\
\hline & Very Good & 25 & 12.16 & 2.03 & 21.44 & 3.96 \\
\hline & Good & 29 & 9.21 & 1.26 & 17.14 & 4.40 \\
\hline & Acceptable & 19 & 5.00 & 1.49 & 12.42 & 4.00 \\
\hline & Total & 87 & 10.26 & 4.00 & 18.66 & 5.87 \\
\hline
\end{tabular}

It is clear from Table 6that the mean of the achievement of students of the experimental group with excellent university grade point average on the post-test was $(27.80)$ with a standard deviation of (2.39), while the achievement of the control group students with excellent educational achievement was (23.89) with a standard deviation of (3.02).

It is evident from the above that there are apparent differences that favor the experimental group with an excellent university grade point average. An associated two-way analysis (ANCOVA) with factor design (2x4) was applied to test the significance of the differences between the averages for the achievement of the two groups (experimental and control), and the cumulative average of the groups (excellent, very good, good, acceptable), and the interaction between the group and the university cumulative average.Table 7 shows the results.

Table 7: Results of the Associated Dual Variation Analysis (ANCOVA) for the Performance of Students, Members of the Study Sample, on Testing the Concepts of Scientific Research Curricula for the Experimental and Control Groups According to the University Grade Point Average.

\begin{tabular}{|l|c|c|c|c|c|}
\hline Source of Variance & $\begin{array}{c}\text { Sum of } \\
\text { Squares }\end{array}$ & $\begin{array}{c}\text { Degree of } \\
\text { Freedom }\end{array}$ & $\begin{array}{c}\text { Average of } \\
\text { Squares }\end{array}$ & $\begin{array}{c}\text { Calculated F } \\
\text { Value }\end{array}$ & $\begin{array}{c}\text { Statistical } \\
\text { Significance }\end{array}$ \\
\hline Pre-test & $\mathbf{2 6 6 . 3 2 2}$ & $\mathbf{1}$ & $\mathbf{2 6 6 . 3 2 2}$ & 66.950 & $0^{\circ} .000^{*}$ \\
\hline Group/Teaching Method & 364.799 & 1 & 364.799 & 91.707 & $0.000^{*}$ \\
\hline University Cumulative Average & 10.031 & 3 & 3.344 & 0.841 & 0.476 \\
\hline Teaching Method * University Cumulative Average & 39.931 & 3 & 13.310 & 3.346 & $0.023^{*}$ \\
\hline Error & 310.276 & 78 & 3.978 & & \\
\hline Adjusted Total & 2965.655 & 86 & & & \\
\hline
\end{tabular}

The results of the accompanying binary variance analysis shown in Table 7 showed that there was no statistically significant effect attributable to the university cumulative average at the level of significance ( $\alpha=0.05)$ where the calculated value of $(\mathrm{F})$ reached (o.841) and its statistical significance was higher than the value (0.05). Through the adjusted calculated averages shown in Table8, it is noted that the adjusted calculated mean for the scores of students of the experimental group with an 
excellent GPA on testing the concepts of scientific research methods (19.859) is a point and with a standard error of (1.318), while for those with a GPA acceptable for the same test was (21.486) points and the standard error (o.925). The mean of the students'score for the control group with an excellent cumulative average on the concepts of scientific research curricula was (17.703) points and with a standard error of (1.007), while for those with a cumulative average accepted on the same test (15.714) points and a standard error of (1.035). The adjusted total meanfor the members of the experimental group reached (20.97) points, while the adjusted total calculated average for the members of the control group was (16.42) points, meaning that the differences favormembers of the experimental group according to the cumulative average variable. In addition, it is clear from Table 9 that the university's cumulative average variable has caused a small variation in the acquisition of concepts of scientific research curricula and their learning among students of the study sample, because the effect of the university cumulative average in the concepts of scientific research curricula (dependent variable) was small, using eta squared $\left(\eta^{2}\right)$ was found to be (o.003). Thus, it explains $(0.33 \%)$ of the total variance in learning the concepts of scientific research methods among students of the study sample.

This result explains that the improved performance of students in acquiring concepts of scientific research methodology is primarily due to the teaching strategy of the KWLH learning schedule. It has been able to play an important role in improving student learning with different cumulative rates (excellent, very good, good, acceptable). With their different levels and capabilities students are able todeepen their understanding and build the meaning of the topics of the lesson. They formulate meaning in the light of the implementation of the teaching strategy procedures based on brainstorming, taking into account the student's previous information, determining what they want to learn, and showing what they have already learned at the end of the educational situation according to the perspective of this KWLH strategy, and this is already shown by the modified calculated averages shown in Table 8.

\section{Table 8:}

\begin{tabular}{|l|l|c|c|c|}
\hline Group & Grades & Numbers & Modified Calculated Average & Standard Error \\
\hline \multirow{5}{*}{ Experimental } & Excellent & 5 & 19.859 & 1.318 \\
\cline { 2 - 5 } & Very Good & 13 & 21.286 & 0.655 \\
\cline { 2 - 5 } & Good & 15 & 21.276 & 0.534 \\
\cline { 2 - 5 } & Acceptable & 9 & 21.486 & 0.925 \\
\cline { 2 - 5 } & Total & 42 & 20.977 & 0.362 \\
\hline \multirow{5}{*}{ Total } & Excellent & 9 & 17.703 & 0.601 \\
\cline { 2 - 5 } & Very Good & 12 & 17.085 & 0.556 \\
\cline { 2 - 5 } & Good & 14 & 15.213 & 1.035 \\
\cline { 2 - 5 } & Acceptable & 10 & 15.714 & 0.302 \\
\cline { 2 - 5 } & Total & 45 & 16.429 & 0.027 \\
\hline & Excellent & 14 & 18.781 & 0.399 \\
\cline { 2 - 5 } & Very Good & 25 & 19.186 & 0.864 \\
\cline { 2 - 5 } & Good & 29 & 18.244 & 0.234 \\
\cline { 2 - 5 } & Acceptable & 19 & 18.600 & 18.703 \\
\cline { 2 - 5 } & Total & 87 & & 0.477 \\
\hline
\end{tabular}

Table 9: EtaSquaredValues and the Explanatory Contrast Ratio for the Performance of Students of the Study Sample on the Acquisition of Scientific Research Curriculum Concepts, According to Teaching Strategy and University Grade Point Average.

\begin{tabular}{|l|c|c|c|c|}
\hline Source of Variance & Sum of Squares & ETA Squared & Percentage Variance Explanation & Effect Size \\
\hline Pretest & 266.322 & 0.0898 & $8.9 \%$ & \\
\hline Group/Teaching Method & 364.799 & 0.123 & $12.3 \%$ & Large \\
\hline
\end{tabular}




\begin{tabular}{|l|c|c|c|c|}
\hline Source of Variance & Sum of Squares & ETA Squared & Percentage Variance Explanation & Effect Size \\
\hline Cumulative Average & 10.031 & 0.003 & $0.33 \%$ & Small \\
\hline $\begin{array}{l}\text { Teaching Method } \\
{ }^{*} \text { Cumulative Average }\end{array}$ & 39.931 & 0.0134 & $1.34 \%$ & Small \\
\hline Error & 310.276 & & & \\
\hline Modified Total & 2965.655 & & & \\
\hline
\end{tabular}

Results related to the fifth question which states: Is there an effect of the interaction between the teaching strategy and the university cumulative average in acquiring concepts of scientific research curricula among students of Princess Rahma University College?

To answer this question, the calculated mean and the standard deviation of students'grades were extracted on a test of the degree of students' acquisition of the concepts of scientific research methods, and by testing the significance of the apparent differences between the calculated means of post-performance on the test for the two groups (experimental and controlling) according to the cumulative average variable (excellent, very good, good, acceptable ), and the interaction between the teaching strategy (the group) and the cumulative average using the two-way analysis of co-variability (ANCOVA) with a global design $\left(2 \mathrm{X}_{4}\right)$, as shown in Table 7 . The results in the table indicate the presence of a statistically significant effect attributed to the interaction between the teaching strategy and the university cumulative average at the level of significance $(\alpha=0.05)$ in acquiring the concepts of scientific research methods, where the calculated value of $(F)$ reached (3.346) and the statistical significance has a value lower than the value (0.05). To find the effect of the interaction between the teaching strategy and the university cumulative average in acquiring the concepts of scientific research methods, the effect size was found using eta square $\left(\eta^{2}\right)$ and the ratio of the variance (prediction) explained as shown in Table 9, which shows that the size of the interaction effect was small, as it was found to be (o.0134) which is a small impact size, and this means that the size of the interaction effect between the teaching strategy and the university cumulative average created a small difference in the acquisition of concepts of scientific research methods (the dependent variable) and thus it explains (1.34\%) of the total variation in the acquisition of the concepts of scientific research curricula among students of the study sample. It is clear from Figure 2 that the performance of students with different cumulative rates (excellent, very good, good, acceptable) in the experimental group that studied with the teaching strategy KWLH was better than the performance of the students in the control group that studied with the usual strategy. The results are in favor of the experimental group. This means that the two variables work cumulatively and not independent of each other in field of acquiring the concepts of scientific research curricula; however, the effect is due to the teaching strategy in the first place. The impact of the KWLH teaching strategy is significant compared to the size of the effect of the interaction between the teaching strategy and the cumulative average that was small in the dependent variable (the acquisition of concepts of scientific research methods).

In this context, it is noted that students with a good and acceptable rate responded to the teaching strategy KWLH effectively reflected on their performance in the post-test positively and benefited from it in enhancing understanding and the formation of knowledge and meaningful learning as their peers with high cumulative high levels excellent and very good in the experimental group and this is evident in the test results, the pre-test, and post-test shown in Table 8 and the adjusted calculated averages presented in Table 9. For example what was found in the results of the members of the experimental group, as the adjusted calculated mean for the achievement of students with excellent grade point averages,the test reached (19.85) points; the mean for the achievement of students with a very good GPA on the test was (21.28) points; then the mean for the achievement of students with a good GPA on the test was (21.27) points, followed by the mean for the achievement of students with an acceptable GPA on the test reached (21.48). This is a clear indication that the students with an acceptable and good average had a clear response and interaction with the teaching strategy that aims through its application to be a difference and a variance in the positive direction in 
the post-performance of the students of the study sample (the experimental group) compared with (the control group).

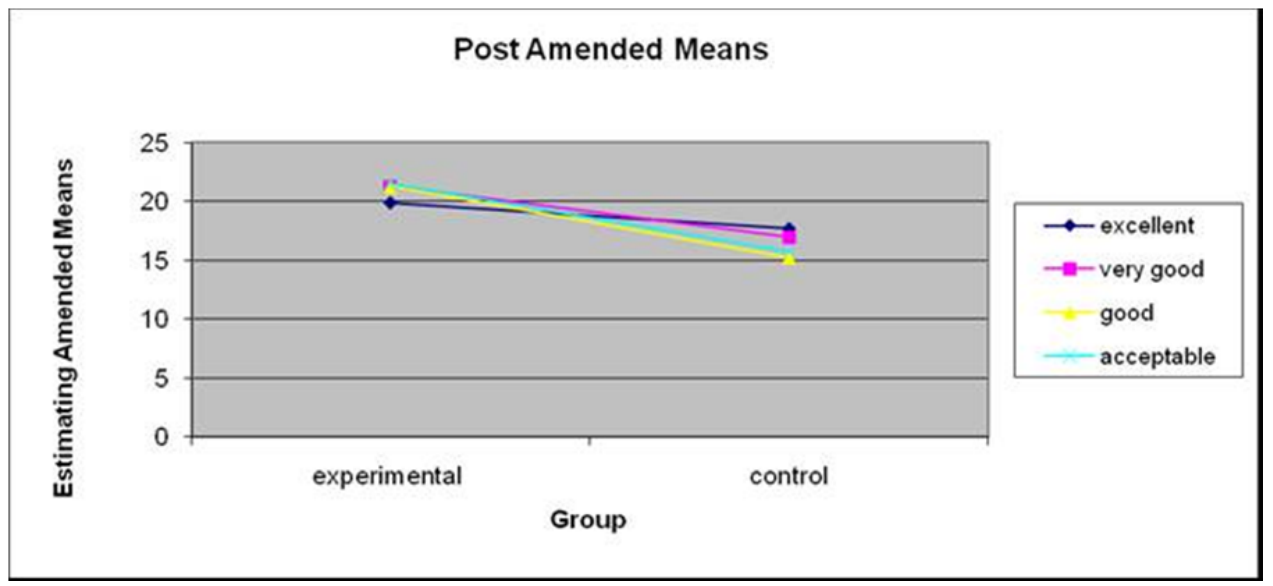

Figure 2: Interaction Between the Teaching Strategy and the GPA in Gaining Concepts of Scientific Research Methods.

\section{Recommendations}

In light of the results and the conclusions reached in this study, it is possible to come up with the following recommendations:

1. Adopting the teaching strategy based on the KWLH learning schedule in the educational process when teaching the various scientific courses because of its effective role in improving students'learning, improving students' acquisition of concepts, and enhancing their learning positively.

2. Giving more importance when developing courses and curricula at the university and school levels for the topic of constructive learning, concepts and meaningful learning based on linking new learning to previous knowledge.

3. Conduct studies on the topic of learning concepts at the undergraduate level in the light of employing the KWLH strategy when teaching scientific subjects in different academic disciplines. This would be in accordance with other variables such as estimating the importance of learning based on understanding and its role transferring the impact of knowledge acquired functionally in life, and the trends of educational elements such as the student and the teacher and the educational supervisor toward this teaching strategy, as well as according to other taxonomic variables such as the type of university (governmental, private) and specialization (scientific, humanistic), as well as conducting analytical studies on books related to academic research methods approved for teaching at the university level in terms of degree and the nature of its handling of subjects.

\section{References}

Alawin, F. and Al-Ayasrah, A. (2016). Building a strategy that integrates two strategies based on the principles of structural theory and measuring its impact on the acquisition of environmental concepts in the ninth grade and the development of their attitudes towards the environment. TheJordanian Journal of Educational Sciences, 12 (2), 155-167. 
Al-Balawi, A. (2016). The effect of teaching using (KWL) strategy on the achievement of students of theoretical specializations at the college of science and arts in al-ula in the subject of statistical applications in the humanities. International Specialized Educational Journal, 5 (5): 240-255.

Al-Subaie, J. and Al-Turki, K. (2016). The effectiveness of teaching with (KWL) strategy in correcting misunderstanding patterns in some concepts of the automatic sensory course for first year high school students. Journal of Educational Sciences, Second Issue (Part 1): 668-717.

Al-Otaibi, F. (2015). The effectiveness of a strategy (KWLH) in teaching the prophetic biography on developing moral awareness and awareness of it among primary school students. Unpublished Master Thesis, Taif University, Kingdom of Saudi Arabia.

Alsoudi, K. (2017). The effect of using K.W.L strategy upon acquiring religious concepts. World Journal of Education, 7(2),31-38.

Bou Aisha, W. (2018). Using the self-schedule strategy (KWL) to teach the computer course to develop academic achievement for first-year high school students in Dhahran, Saudi Arabia. The Scientific Journal of the Faculty of Education - Assiut University, 34 (4): 413 - 438.

Hamdan, M. (2014). KWL-Plus Effectiveness on Improving Reading Comprehension of Tenth Graders of Jordanian Male Students. Theory and Practice in Language Studies, 4(11), 2278-2288.

Kusumaningrum, I.\& Widiyanto, W. (2018). Theuse of K-W-L (Know-Want-Learn) strategy to improve students' reading skill in descriptive text for the eighth grade students of SMPN 1 pecangaanjepara in academic year of 2017/2018.ETERNAL (English Teaching Journal), 9(1), 86- 98.

Mardiana.M.(2016). Using KWL strategy to enhance reading comprehension achievement and characters of the seventh grade students of SMPN 1 babatsupat, musibanyasin.Journal of English Literacy Education, 3(2), 135147 .

Muhammad, M. (2013). The effect of using (KWL) strategy in teaching mathematics on the academic achievement of sixth graders in the eastern region. The winner of the Sharjah Prize for Educational Excellence and Excellence (Distinguished Applied Educational Research Category), 19th Session, Sharjah Education Council, United Arab Emirates.

Musabalat, J. (2016). The effect of using (KWL) strategy on the achievement of fifth grade students in reading and their attitudes towards learning in public schools in the Nablus governorate. Unpublished Master Thesis, AnNajah National University, Nablus, Palestine.

Riswanto, Risnawati, Lismayanti. (2014). The Effect of Using KWL (Know, Want, Learned) Strategy on EFL Students' Reading Comprehension Achievement. International Journal of Humanities and Social Science, Vol. 4, 7(1), 225-233.

Aram, Merfat. (2012). The effect of using (KWL) strategy on acquiring concepts and skills of critical thinking in science among seventh graders. Unpublished Master Thesis, Islamic University - Gaza, Palestine.

Woyengibarakemi Soinyo, S. \& Brown, T. (2019). Effect of know- want- learn (KWL) differentiation and JIGSAW cooperative learning strategies on students' performance in social studies. British Journal of Education, $7(8)$, 45-54.

Zouhor, Z. \& Bogdanović, I. \& Skuban, S. \& Pavkov-Hrvojević, M. (2017). The effect of the modified know-wantlearn strategy on sixth-grade students' achievement in physics. Journal of Baltic Science Education, 16(6), 946-957. 